\title{
Health Related Quality of Life of Diabetic and Non- Diabetic Elderly in a Municipality of Central Nepal
}

\author{
Srijana Sapkota, 'Jiwan Kumar Poudyal, ${ }^{1,2}$ Rajani Shah,' Kanchan Thapa ${ }^{2}$ \\ 'Shree Medical and Technical College, Bharatpur, Chitwan, Nepal, ${ }^{2}$ Central Department of Population Studies (CDPS), Tribhuvan \\ University, Kirtipur, Nepal.
}

\begin{abstract}
\section{Introduction}

Quality of life (QoL) is the perception of an individual about their position in life. Chronic diseases such as diabetes are said to have influence on QoL. Health condition changes with increased age and chronic disease condition. This study aimed to assess Health-Related QoL of diabetic and non-diabetic elderly.
\end{abstract}

\section{Methods}

A community based cross-sectional study was conducted among 167 elderly in Gaindakot municipality of Nawalpur, Nepal. Health related QoL was assessed using World Health Organization QoL Instrument scale. Data was analyzed using descriptive as well as inferential statistics.

\section{Results}

Among the diabetic respondents, highest mean score was obtained in social relationship (68.76), whereas environmental health (69.02) holds highest mean score among non-diabetic. Nondiabetics were in better position in terms of both psychological (63.23 vs 55.77) and physical health (62.23 vs 57.15) than diabetics. Overall QoL and overall health perception were found to be significantly correlated with all domains of QoL at $(\mathrm{p}<0.05)$ and $(\mathrm{p}<0.01)$ respectively among diabetics. Age group, gender, educational status, marital status and employment status were found to be statistically associated with different domains of QoL in both groups but caste, family type smoking and alcohol intake didn't show any association with any of the domain of QoL in both groups.

\section{Conclusions}

Three domains of Health Related QoL (physical, psychological and environmental health) except social relationship were better among non-diabetic compared to that of diabetic respondents. Preventing diabetes and focusing on physical, psychological and environmental health of diabetics are required for a healthy elderly life.

Keywords: eiabetic; elderly; health-related quality of life; Nepal, non-communicable diseases.

Correspondence: Srijana Sapkota, Shree Medical and Technical College, Bharatpur, Chitwan, Nepal. Email: srizanaspkt98@gmail.com. Phone: +977-9801346236. 


\section{INTRODUCTION}

Globally, it is estimated that population aged over 60 years will nearly double in between 2015 and 2050 from 12 to 22 percent. ${ }^{1}$ Two thirds of the world's older persons live in the developing regions, where their numbers are growing faster. In 2050 , it is expected that nearly 8 in 10 of the world's older persons will be living in the developing regions. ${ }^{2}$ According to the census 2011, there is about nine percent of aging population in Nepal. ${ }^{3}$

Diabetes is a condition when the pancreas is no longer able to make insulin or when human body cannot utilize the insulin that body produces. ${ }^{4}$. It is found that diabetes is more prevalent among higher age group people. Despite of having good knowledge on diabetes, people are unlikely to change their lifestyle ${ }^{5}$. In low and middle-income countries, prevalence of diabetes is increasing ${ }^{6}$. It is estimated that diabetes will be the seventh leading cause of death globally by $2030{ }^{7}$. A survey conducted in Nepal showed prevalence of diabetes all age group (15-69 year) population in 2019 compared to 2013 study, revealed that elderly are more vulnerable to diseases such as diabetes ${ }^{8}$. Death due to non-communicable diseases (NCDs) contributes to $66 \%$ of the total deaths in Nepal ${ }^{9}$. Thus, epidemics of NCDs has been recognized and multi sectoral action plan (2014-20) has been endorsed for prevention and control of NCDs, in which emphasis has been given to halting the rise in obesity and diabetes ${ }^{10}$. Sustainable Development Goal 3 mentions about ensuring healthy life and promoting well-being for all at all ages and its target 3.4 states reducing premature mortality from NCDs by one third through prevention and treatment, and promoting mental health and wellbeing ${ }^{11}$. Thus, prevention and control of NCDs have been emphasized throughout the world which ultimately promotes the healthy well-being contributing to Quality of life (QoL).

Furthermore, past studies in Nepal on QoL of elderly and chronically ill focused on loneliness ${ }^{12}$, depression ${ }^{13,14}$, functional disability ${ }^{15}$, self-reported health ${ }^{16}$, abuse of elderly ${ }^{17}$, Hypertension ${ }^{18}$ and Human Immunodeficiency Virus ${ }^{19}$. Some studies have assessed the QoL of diabetic patients in clinical setting ${ }^{20,21}$. However, there are limited studies conducted to assess the QoL of diabetic patients in community setting in Nepal. This study aimed to assess the Physical health, Psychological health, Social relationship and Environmental health domains of Health Related QoL (HRQoL) of diabetic and non-diabetic elderly in community setting.

\section{METHODS}

A cross sectional study was done in ward number 1 of Gaindakot municipality of Nawalpur district. People aged 60 and above, who were resident of the selected ward, were considered for this study. The sample size of 167 was calculated for the study keeping the average prevalence $50 \%$ as exact prevalence was not found, with $8 \%$ margin of error and $10 \%$ non-response. Among the total sample, 53 were diabetic participants and the remaining ones were non-diabetic. Samples size was determined by using the following formula:

$$
n=Z^{2} \mathrm{pq} / \mathrm{d}^{2}
$$

Where, $\mathrm{n}=$ Desired Sample size

$Z=$ Value of $Z$ - Score=1.96, assuming standard normal distribution at $95 \%$ confidence level

$\mathrm{P}=$ proportion $=50 \%=0.5$

$q=(1-p)=(1-0.5)=0.5$

$\mathrm{d}=$ desirable error $=0.08$ (margin of error)

By using formula

$\mathrm{n}=(1.96)^{2} \times 0.5 \times 0.5$

$$
(0.08)^{2}
$$

Therefore, desired sample size was $(n)=150.062$

When $10 \%$ non-response was considered, the final sample size $=167$. 
Structured questionnaire was used for data collection. The questionnaire consisted of sociodemographic characteristics of the respondents and World Health Organization QoL Instruments (WHOQoL-BREF) questionnaire was used to assess the HRQoL. Pretesting was done on 20 people of same group of ward number 5 of Gaindakot municipality. Modification on questionnaire was done through findings of pretesting. Some of demographic characteristics were then removed from questionnaire.

The WHOQoL-BREF questionnaire consists of 26-items of WHOQoL-100 version. The WHOQoL-BREF contains 2 items for the overall QoL and general health, and 24 items of satisfaction that are divided into 4 domains ${ }^{22}$. Each item is rated on a 5-point Likert scaleand respondents were asked to answer how good or satisfied they felt in their life over last two weeks.

1. Physical health domain: Activities of daily living, Dependence on medicinal substances and medical aids, Energy and fatigue, Mobility Pain and discomfort, Sleep and rest and Work Capacity.

2. Psychological health domain: Bodily image and appearance, Negative feelings, Positive feelings, Self-esteem, Spirituality / Religion / Personal beliefs, Thinking, Learning, Memory and Concentration.

3. Social relationship domain: Personal relationships, Social support, Sexual activity.

4. Environmental health domain: Financial resources, Freedom, physical safety and security, Health and social care: accessibility and quality home environment, Opportunities for acquiring new information and skills, Participation in and opportunities for recreation / leisure activities, Physical environment (pollution/noise /traffic/ climate) and Transport.
5. Overall QoL: The overall QoL is calculated by using mean score obtained from the first question of WHOQoL-BREF, i.e. how would you rate your QoL?

6. Overallhealth:Theoverallhealthis calculated by using mean score obtained from the second question of WHOQoL-BREF, i.e how satisfied is you with your health?

Data collection was done from $18^{\text {th }}$ June to $7^{\text {th }}$ July, 2019 by the first author. A list of diabetic people of the selected ward was obtained from "Gaindakot Diabetes Community". Each house of the ward was also screened for an elderly with diabetes by making house-to house visit. In the field more people were found with diabetes than in the list. Out of 59 diabetic people found during data collection, 53 were included in the study as six did not respond. The remaining 114 elderly included in the study were non-diabetic. Face to face interview was conducted for data collection. Two steps were followed to assess the presence of diabetes. At first, the participants were asked whether they had diabetes or not. Secondly, when they responded positively, they were asked to show the evidence of having diabetes (physician prescription or the medicine they were using regularly).

The collected data was entered and analyzed in SPSS 16 version. The raw score was calculated using the formula given in the WHO guidelines. Then the calculated raw score was changed into (0-100) transform score according to the guidelines $^{22}$. Independent t-test or ANOVA were applied to compare the mean scores of different variables and domains. P-value $<0.05$ was considered significant.

Ethical approval was taken from Shree Medical and Technical College-Institutional Review Committee (SMTC-IRC-2020720-1). Written permission was taken from the local authority. Since some of the participants could not read 
and write, we took verbal informed consent from the participants before starting the interview. Voluntary participation of the respondents was ensured throughout the study. They were ensured that the collected information will only be used for the research purpose.

\section{RESULTS}

Socio-demographic characteristics: In the present study, More males (35.4\%) than females were diabetic $(28.4 \%)$. A higher percentage of elderly in age group 60-69 years (36.6\%) than 70 -
79 years (25\%) and 80 and above years (34.4\%) were diabetic. More Janajati/Dalit (41.17\%) than Brahmin/Chhetri (30.6\%) was diabetic. Higher percentage of elderly living in joint family (34.6\%) than in nuclear family $(22.5 \%)$ was diabetic. More literate $(33.0 \%)$ than illiterate (30.0\%) were diabetic. Regarding marital status, higher percentage of single elderly (33.3\%) than married (31\%) were diabetic. More employed (41.9\%) than unemployed (29.4\%) were diabetic. More smokers (40\%) and fewer alcoholics $(28.6 \%)$ were diabetic (Table 1$)$.

Table 1. Distribution of characteristics of respondents $(n=167)$

\begin{tabular}{|c|c|c|c|c|}
\hline \multirow{2}{*}{ Characteristics } & \multicolumn{2}{|c|}{ Diabetic } & \multicolumn{2}{|c|}{ Non-diabetic } \\
\hline & Frequency & Percent & Frequency & Percent \\
\hline \multicolumn{5}{|l|}{ Gender } \\
\hline Male & 28 & 35.4 & 51 & 64.6 \\
\hline Female & 25 & 28.4 & 63 & 71.59 \\
\hline \multicolumn{5}{|l|}{ Age group (Years) } \\
\hline $60-69$ & 26 & 36.6 & 45 & 63.38 \\
\hline $70-79$ & 16 & 25.0 & 48 & 75.0 \\
\hline 80 and above & 11 & 34.4 & 21 & 65.6 \\
\hline \multicolumn{5}{|l|}{ Caste } \\
\hline Brahmin/Chhetri & 46 & 30.6 & 104 & 69.4 \\
\hline Janajati/Dalit & 7 & 41.17 & 10 & 58.82 \\
\hline \multicolumn{5}{|l|}{ Family types } \\
\hline Nuclear & 9 & 22.5 & 31 & 77.5 \\
\hline Joint & 44 & 34.6 & 83 & 65.4 \\
\hline \multicolumn{5}{|l|}{ Educational level } \\
\hline Illiterate & 21 & 30.0 & 49 & 70.0 \\
\hline Literate & 32 & 33.0 & 65 & 67.0 \\
\hline \multicolumn{5}{|l|}{ Marital status } \\
\hline Married & 38 & 31.1 & 84 & 68.9 \\
\hline Single/Widow & 15 & 33.3 & 30 & 66.7 \\
\hline \multicolumn{5}{|l|}{ Employment status } \\
\hline Employed/retired & 13 & 41.9 & 18 & 58.1 \\
\hline Unemployed & 40 & 29.4 & 96 & 70.6 \\
\hline \multicolumn{5}{|l|}{ Smoking } \\
\hline No & 39 & 29.5 & 93 & 70.5 \\
\hline Yes & 14 & 40.0 & 21 & 60.0 \\
\hline \multicolumn{5}{|l|}{ Alcohol intake } \\
\hline No & 51 & 31.9 & 109 & 68.1 \\
\hline Yes & 2 & 28.6 & 5 & 71.4 \\
\hline
\end{tabular}


QoL score of diabetic and non-diabetic respondents

Comparison of the four dimensions of QoL between diabetic and non-diabetic respondents is shown in shows that physical health (63.23 \pm 1.3$)$, psychological health $(63.23 \pm 1.46)$ and environmental health $(69.02 \pm 1.23)$ were better among non-diabetic than diabetic physical health $(57.15 \pm 1.77)$, psychological health $(55.77 \pm 12.91)$ and environmental health $(68.37 \pm 1.16)$. There was less difference on social relationship for diabetic $(69.76 \pm 2.36)$ and nondiabetic $(68.37 \pm 1.16)$ (Table 2).

\begin{tabular}{|r|c|c|}
\hline \multicolumn{3}{|c|}{$\begin{array}{l}\text { Table 2. QoL score of the diabetic and non-diabetic } \\
\text { respondents }\end{array}$} \\
\hline Domains & Diabetic ( $\mathbf{n}=53)$ & $\begin{array}{c}\text { Non-diabetic } \\
(\mathbf{n}=114) \\
\text { Mean (SD) }\end{array}$ \\
\cline { 2 - 3 } $\begin{array}{r}\text { Mhysical } \\
\text { health }\end{array}$ & $57.15(12.91)$ & $62.23(13.91)$ \\
\hline $\begin{array}{r}\text { Psychological } \\
\text { health }\end{array}$ & $55.77(16.44)$ & $63.23(15.59)$ \\
\hline $\begin{array}{r}\text { Social } \\
\text { relationship }\end{array}$ & $68.76(14.55)$ & $68.37(10.64)$ \\
\hline $\begin{array}{r}\text { Environmental } \\
\text { health }\end{array}$ & $68.37(13.05)$ & $69.02(13.15)$ \\
\hline
\end{tabular}

Correlation of overall QoL and overall health with four domains of HRQoL: Overall QoL was found to be statistically correlated $(\mathrm{P}<0.01)$ with all four domains of QoL among diabetics whereas overall QoL was found to be statistically associated with psychological $(\mathrm{P}<0.05)$ and environmental health $(\mathrm{P}<0.01)$ among nondiabetics.

Overall health was found to be statistically associated $(\mathrm{P}<0.01)$ with all four domains of QoL among diabetics whereas it was found to be statistically associated with only psychological health $(\mathrm{P}<0.05)$ among nondiabetics (Table 3).

Socio-demographic factors associated with four domains of HRQoL: Age group and educational status were statistically associated with all three domains of QoL except social relationship among diabetics, whereas only physical health among non-diabetic was found to be statistically associated $(p=0.005)$ with age group. Psychological and environmental health were found to be significantly associated $(p=0.002$ and $p=0.004)$ respectively with educational status among non-diabetic. Gender was significantly associated $(p=0.015$ and $\mathrm{p}=0.006$ ) with physical health and environmental health respectively among diabetic whereas only with environmental health $(\mathrm{p}=0.02)$ among non-diabetic. Marital status was significantly associated $(p=0.019)$ with physical health only among diabetic whereas all domains were significantly associated $(\mathrm{p}<0.05)$ with marital status among non-diabetic. Employment status was found to be significantly associated with psychological health $(\mathrm{p}=0.02)$ among diabetic and physical health $(p=0.005)$ among non-diabetic. Caste,

Table 3. Correlation of overall QoL and overall health with four domains of HRQoL

\begin{tabular}{|c|c|c|c|c|c|c|c|c|c|}
\hline \multirow{2}{*}{\multicolumn{2}{|c|}{ Characteristics }} & \multicolumn{2}{|c|}{ Physical health } & \multicolumn{2}{|c|}{ Psychological health } & \multicolumn{2}{|c|}{ Social relationship } & \multicolumn{2}{|c|}{ Environmental health } \\
\hline & & \multirow{2}{*}{$\begin{array}{c}\begin{array}{c}\text { Non- } \\
\text { Diabetic }\end{array} \\
0.215\end{array}$} & \multirow{2}{*}{$\begin{array}{l}\text { Diabetic } \\
0.342^{* *}\end{array}$} & \multirow{2}{*}{$\begin{array}{c}\begin{array}{c}\text { Non- } \\
\text { Diabetic }\end{array} \\
0.350^{*}\end{array}$} & \multirow{2}{*}{$\begin{array}{l}\text { Diabetic } \\
0.530^{* *}\end{array}$} & \multirow{2}{*}{$\begin{array}{c}\begin{array}{c}\text { Non- } \\
\text { Diabetic }\end{array} \\
0.250\end{array}$} & \multirow{2}{*}{$\begin{array}{l}\text { Diabetic } \\
0.370^{* *}\end{array}$} & \multirow{2}{*}{$\begin{array}{c}\begin{array}{c}\text { Non- } \\
\text { Diabetic }\end{array} \\
0.373^{* *}\end{array}$} & \multirow{2}{*}{$\begin{array}{l}\text { Diabetic } \\
0.434^{* *}\end{array}$} \\
\hline & Pearson Correlation & & & & & & & & \\
\hline & Sig. (2-tailed) & 0.122 & 0.000 & 0.010 & 0.000 & 0.119 & 0.001 & 0.006 & 0.000 \\
\hline \multirow{2}{*}{$\begin{array}{l}\text { Overall } \\
\text { health }\end{array}$} & Pearson Correlation & 0.174 & $0.365^{* *}$ & $0.329^{*}$ & $0.442^{* *}$ & 0.149 & $0.333^{* *}$ & 0.260 & $0.373 * *$ \\
\hline & Sig. (2-tailed) & 0.214 & 0.000 & 0.016 & 0.000 & .359 & 0.002 & 0.060 & 0.000 \\
\hline
\end{tabular}

*Correlation is significant at the 0.05 level (2-tailed), **Correlation is significant at the 0.01 level (2-tailed) 
family type, smoking and alcohol intake were not found to be statistically associated with any domains of QoL in both categories (Table 4).

Table 4. Socio-demographic factors associated with four domains of HRQoL

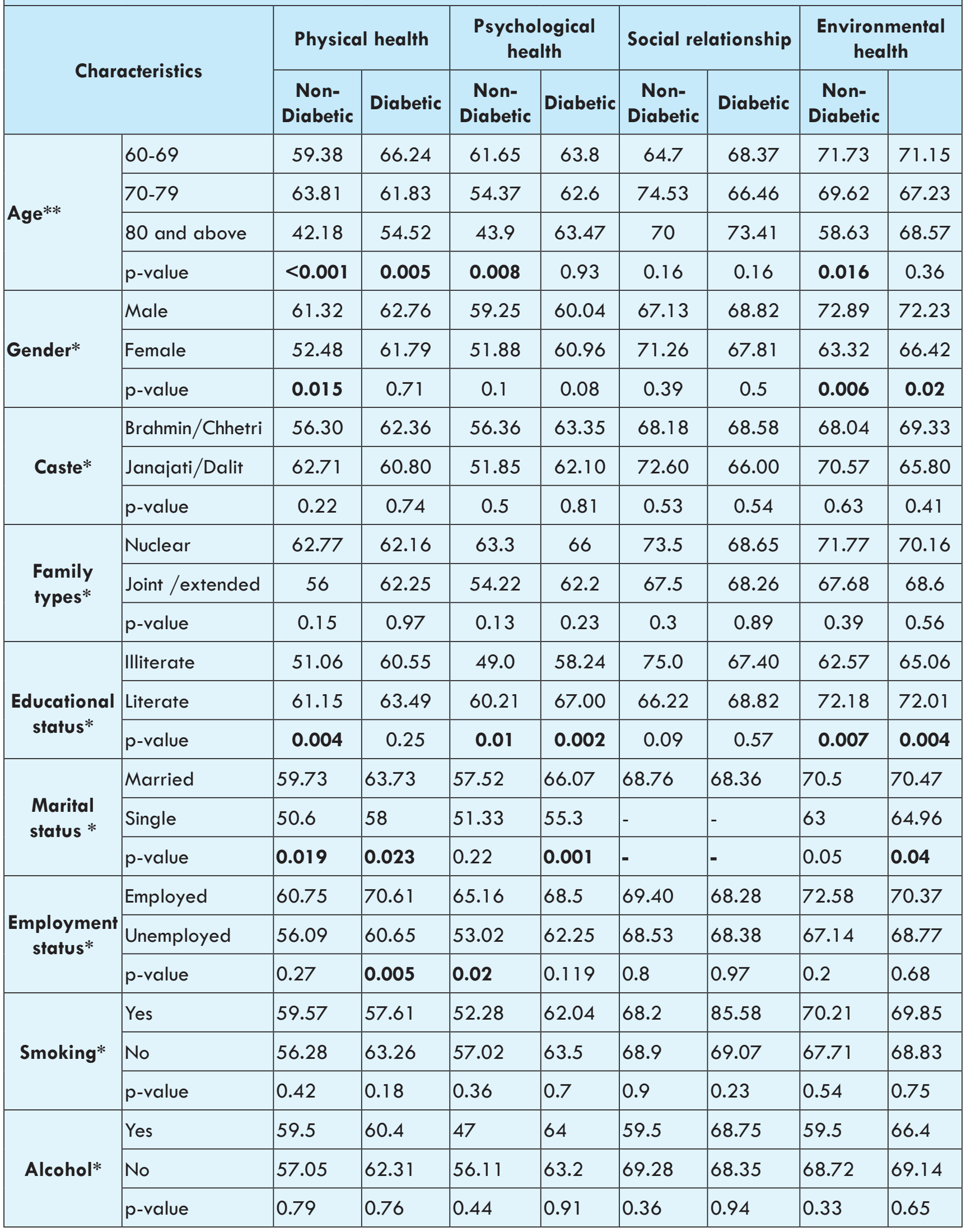




\section{DISCUSSION}

The present study was conducted to assess the difference in HRQoL among diabetic and non-diabetic elderly in Gaindakot, Nawalpur, Nepal as well as the socio-demographic factors associated with four domains of the HRQoL.

In this study, the mean scores of all HRQoL domains except social relationship domain were significantly lower among diabetic group as compared with non-diabetic. Another study from Iran also indicates the mean scores of all HRQoL domains were significantly lower among diabetic group as compared to nondiabetics ${ }^{23}$. A study conducted in Czech and Slovak Republic using the same tool indicate similar findings ${ }^{24}$. Among diabetic group, the maximum and minimum scores were found in social relationship and psychological domain respectively. Another study from Teaching hospital, Nepal also indicated similar results with this study. The study showed that maximum score was for social relationship and minimum score was for physical health ${ }^{25}$. In this study overall QoL and overall health were found to be correlated with all the four domains of QoL among diabetic but among non-diabetic overall QoL was correlated with psychological and environmental health and overall health was correlated with psychological health. Study conducted in females with diabetes at Diabetes Clinic of Khoy city of Iran ${ }^{26}$ and study conducted among heath care staff in Neyshabur health-care centre of $\operatorname{Iran}^{27}$ showed that the overall QoL and overall health were correlated with all domains of QoL. In the current study, physical and environmental health domains had significant association with gender among diabetics. In studies of Tehran, the QoL among diabetic patients had significant association with gender which is partially consistent with the current study ${ }^{28}$. In this study only physical health domain had significant association with gender among non-diabetic. Similar result was obtained in the study done in Rural and Urban Areas of Ambala district of India where both physical and environmental health domains were statistically significant with gender ${ }^{29}$. The findings of the current study revealed that every domain except social relationship had statistically significant relationship with age among diabetic elderly, whereas only physical health was statistically significant with age among non-diabetic. A study conducted in Barabanki District, Uttar Pradesh of India among elderly also found that only physical health domain is significantly associated with age which is similar to the current study ${ }^{30}$. A study from Northwest of Iran conducted in diabetic clinic found association of age with all the four domains among diabetic ${ }^{26}$. In the current study, educational status was found to have significant association with three domains except social relationship. The study conducted in females with diabetes found association with all the four domains ${ }^{26}$. In the current study, marital status was significantly associated with all the domains of the HRQoL among non-diabetics. Another study in rural setting of Kerala, India demonstrated similar findings ${ }^{31}$. Since, husband and wife can be immediate caretaker of each other being married is likely to result in low chance of getting diabetes.

This study has some limitations. One is the small sample size due to time and cost constraints. There may be subjective bias introduced during the interview period. Under reporting of diseases could also be another limitation because only self-reported cases of diabetes were included. We could not study influence of several other factors such as mental health status and complications of chronic morbid conditions of the elderly. In spite of these limitations, this community based cross-sectional study gives valuable information on the QoL difference among diabetic and non- 
diabetic elderly using a standard instrument.

\section{CONCLUSIONS}

Three domains of HRQoL - physical, psychological and environmental health- except social relationship were better among nondiabetic compared to diabetic respondents.

Overall QoL and overall health were correlated with all four domains of HRQoL among diabetic, but overall QoL was correlated with physical and environmental health and overall health was correlated with psychological health among nondiabetic. Age, gender, education, marital status and employment were significantly associated with HRQoL in both diabetic and non-diabetic elderly. Physical health, psychological health and environmental health were associated with age, educational status and marital status. Gender was associated with physical and environmental health, while employment was associated with physical and psychological health. None of the socio-demographic variables were significantly associated with social relationship

\section{REFERENCES}

1. WHO. Ageing and health Fact sheet 2019 [Available from : https://www.who.int/ en/news-room/fact-sheets/detail/ageingand-health].

2. United Nations DoEaSA, Population Division (2017). World Population Ageing 2017- Highlights (ST/ESA/ SER.A/397). .

3. Ministry of Health NNEaI. Nepal Demographic and Health Survey 2016. Kathmandu, Nepal: Ministry of Health, Nepal; 2017.

4. Federation ID. About Diabetes 2019 [Available from : https://idf.org/ aboutdiabetes/what-is-diabetes.html]. in both groups. This study suggests that special attention is required in preventing diabetes, and improving elderly's physical, psychological and environmental health. There should be more emphasis on promoting overall QoL and overall health of elderly as well. Another study with larger sample size can be another recommendation since we conducted study among a small group of community people.

\section{List of abbreviations}

HRQoL: Health Related Quality of Life; NCD: Non-Communicable Disease; SMTCIRC : Shree Medical and Technical CollegeInstitutional Review Committee; QoL: Quality of Life; WHOQoL-BREF: World Health Organization Quality of Life-Bref

\section{ACKNOWLEDGMENTS}

We would like to acknowledge all the participants in the present study.

\section{Conflicts of Interest}

The authors declare no conflicts of interest.

5. Nepal C, Vyas P, Bhattarai R, Acharya B, Thapa K, Shrestha J, et al. Knowledge, attitude and practice of type 2 diabetic patients of selected outreach clinic, Dharan, Nepal. Al Am een J Med Sci. 2017;10.

6. WHO. diabetes fact sheet 2019 [Available from :https://www.who.int/news-room/ fact-sheets/detail/diabetes].

7. Dr Sushil Baral SU, Bipul Lamichhane. Health Research and Social Development Forum (HERD) Thapathali, Kathmandu, Nepal. [https://www.herd.org.np/ uploads/frontend/Publications/Pub licationsAttachments1/1480578900Backgrounder\%20on\%20DIABETES. pdf]. 
8. Dhimal MBB, Bhattarai S, Dixit LP, Hyder MKA, Agrawal N, Rani M, Jha AK. 2020. . Report of Non Communicable Disease Risk Factors: STEPS Survey Nepal . In: Council. NHR, editor. Kathmandu.2019.

9. 2018 WNCp. [available from: https:// www.who.int/nmh/countries/2018/npl_ en.pdf?ua=1].

10. Government of Nepal M. Multisectoral Action Plan on the Prevention and Control of NCD in Nepal 2014-2020. 2016.

11. Commission NP. Nepal's Sustainable Development Goals, Baseline Report, kathmandu,nepal. Government of Nepal, National Planning Commission 2017.

12. HN C. Social Support and its Correlation with Loneliness and Subjective Wellbeing: A Cross-cultural Study of Older Nepalese Adults. Asian social work and policy review 2010;4(1):1-25.

13. Chalise Homnath RSL. Prevalence and correlates of depression among Nepalese Rai older adults. Journal of gerontology and geriatric research. 2013;2(4):1-5.

14. Ghimire S, Baral B, Pokhrel B, Pokhrel A, Acharya A, Amatya D, et al. Depression, malnutrition, and health-related quality of life among Nepali older patients. BMC Geriatrics. 2018;18((1)):191.

15. Chalise HN ST, Kai IJPH. 2008;122(4):3946. Functional disability in activities of daily living and instrumental activities of daily living among Nepalese Newar elderly. Journal of gerontology and geriatric research. 2008;122(4):394-6.

16. Chalise HN, Saito T, Kai I. Self-reported health: a study of older adults from a developing country--Nepal. Bioscience trends. 2007;1(2):102-7.

17. Chalise HaMB. Abuse of older adults residing in the communit y of Nepal. Journal of gerontology and geriatric research. 2017;6(415):2-5.

18. Bhandari N, et al. Quality of life of patient with hypertension in Kathmandu. International journal of nursing science. 2016;3(4): 379-84.

19. Agrawal H, Mourya R, Shrestha R, Agrawal S. Quality of Life Among HIV Positive Individuals in Kathmandu Valley and Eastern Region of Nepal. Kathmandu University medical journal (KUMJ). 2014;10:3-7.

20. Mishra SR, Sharma A, Bhandari PM, Bhochhibhoya S, Thapa K. Depression and Health-Related Quality of Life among Patients with Type 2 Diabetes Mellitus: A Cross-Sectional Study in Nepal. PloS one. 2015;10(11):e0141385.

21. Yekta Z, Pourali R, Ghasemi-Rad M. Comparison of demographic and clinical characteristics influencing health-related quality of life in patients with diabetic foot ulcers and those without foot ulcers. Diabetes, metabolic syndrome and obesity : targets and therapy. 2011;4:393-9.

22. T GT. The World Health Organization Quality of LifeAssessment (WHOQOL): Position paper from the World Health Organization. SocSci Med. 1995.

23. Tavakkoli LD, Azizallah \%J Zahedan Journal of Research in Medical Sciences. Compare the quality of life in type 2 diabetic patients with healthy individuals (application of WHOQOL-BREF). Journal of Research in Medical Sciences. 2017;19(2).

24. Živčicová E, Gullerová M. Quality of Life 
Comparison of People with and without Diabetes Mellitus. CBU International Conference Proceedings. 2015;3:258-62.

25. Mishra SR, Sharma A, Bhandari PM, Bhochhibhoya S, Thapa K. Depression and health-related quality of life among patients with type 2 diabetes mellitus: a cross-sectional study in Nepal. PLoS One. 2015;10(11).

26. Didarloo A, Alizadeh M. Health-related quality of life and its determinants among women with diabetes mellitus: A crosssectional analysis. Nursing midwifery studies. 2016;5(1).

27. Gholami A JL, Zarei E, Dehghan AJIjopm. Application of WHOQOL-BREF in measuring quality of life in health-care staff. International journal of preventive medicine. 2013;4(7):809.

28. Darvishpoor AK, Abed ZS. Health-related quality of life of diabetic patients in tehran.
International journal of endocrinology metabolism. 2013;11(4):e7945-e.

29. Mittal A, Aggarwal A, Nayyar S, Thakral A, Natt HK, Singh A. Assessment of quality of life of the elderly living in rural and urban areas of Ambala District: A comparative study. Journal of Mid-life Health. 2019;10(4):173.

30. Brajesh Anand P, Shukla M, Ahmad S, Soni S. Dimensions and determinants of Quality of Life among elderly in a rural population of Barabanki District, Uttar Pradesh. Indian Journal of Forensic Community Medicine. 2017;4(1):1-6.

31. Thadathil S, Jose R, Varghese. Assessment of domain wise quality of life among elderly population using WHO-BREF scale and its determinants in a rural setting of Kerala. Int J Curr Med Appl Sci. 2015;7:43-6.

Citation: Sapkota S, Poudyal J, Shah R, Thapa K. Health Related Quality of life of Diabetic and Non-Diabetic Elderly in a Municipality of Central Nepal. JCMS Nepal. 2021 ; 17(2); 170-79. 